\title{
EPISTAKSIS DI POLIKLINIK THT-KL BLU RSUP PROF. DR. R. D. KANDOU MANADO PERIODE JANUARI 2010-DESEMBER 2012
}

\author{
${ }^{1}$ Merry Pricilia Limen \\ ${ }^{2}$ Ora Palandeng \\ ${ }^{2}$ Ronny Tumbel
}

\author{
${ }^{1}$ Kandidat Skripsi Fakultas Kedokteran Universitas Sam Ratulangi Manado \\ ${ }^{2}$ Bagian Ilmu Kedokteran THT-KL Fakultas Kedokteran Universitas Sam Ratulangi Manado \\ Email:prizilia_ei@yahoo.com
}

\begin{abstract}
Epistaxis is bleeding from the nose. Epistaxis may be caused by local or systemic factors. Local factors can be caused by chronic sinusitis, foreign bodies, irritants, and trauma. Systemic factors can be caused by hypertension, leukemia, liver cirrhosis, or drugs (Anti Inflammatory Drugs). There are two sources of bleeding in epistaxis, anterior part sourced from Kiesselbach plexus, posterior part sourced from sphenopalatine artery and posterior ethmoidal artery. This study is a descriptive observational study. The purpose of this study was to determine epistaxis in Department of Otolaryngology Prof. DR. R.D. Kandou General Hospital of Manado. The result of this study found 1048 cases of epistaxis from 12.981 visitors during January 2010 - December 2012. The incidence of patients with epistaxis 8,07\%. The incidence in male is higher than female. Patients with epistaxis more common in the age groop 25-44 years. The most common cause of epistaxis is by systemic cause $(58,49 \%)$.
\end{abstract}

Keywords: epistaxis.

\begin{abstract}
Abstrak: Epistaksis adalah keluarnya darah dari hidung yang penyebabnya bisa lokal atau sistemik. Penyebab lokal dapat diakibatkan oleh sinusitis kronis, benda asing, iritan, dan trauma. Penyebab sistemiknya dapat disebabkan oleh hipertensi, leukemia, sirosis hati, ataupun obatobatan (Anti Inflammatory Drugs). Terdapat dua sumber perdarahan pada epistaksis yaitu pada bagian anterior, beRSUPmber dari pleksus Kiesselbach (little area) dan pada bagian posterior yang berasal dari arteri sfenopalatina dan arteri etmoid posterior. Tujuan dari penelitian ini adalah untuk mengetahui epistaksis di poliklinik THT-KL RSUPP Prof. DR. R.D. Kandou Manado periode Januari 2010 - Desember 2012. Penelitian ini menggunakan metode deskriptif observasional. Hasil penelitian ini diperoleh 1048 kasus dari jumlah pengunjung 12.981 selama periode Januari 2010 - Desember 2012. Insiden penderita epistaksis 8,07\%. Angka kejadian pada laki-laki lebih tinggi dibandingkan perempuan. Penderita epistaksis lebih banyak ditemukan pada kelompok umur 25-44 tahun. Penyebab tersering epistaksis adalah penyebab sistemik (58,49\%).
\end{abstract}

Kata kunci: epistaksis.

Epistaksis banyak dijumpai sehari-hari baik pada anak maupun usia lanjut. Epistaksis seringkali merupakan gejala atau manifestasi penyakit lain. Kebanyakan ringan dan dapat berhenti tanpa bantuan medis, tetapi epistaksis yang berat, walaupun jarang, merupakan masalah kedarutan yang dapat berakibat fatal bila tidak segera ditangani.
Epistaksis adalah masalah medis umum, dimana sekitar $60 \%$ penduduk akan mengalami setidaknya satu kali episode epistaksis seumur hidup dan diantaranya hanya 6\% dari penderita epistaksis yang mencari bantuan medis.

Prevalensi epistaksis pada pria dan wanita umumnya adalah sama, dan 
distribusi umur penderita epistaksis biasanya terjadi pada usia $<20$ tahun dan $>40$ tahun. ${ }^{3}$

Pada Januari 2002 sampai Agustus 2007 berdasarkan penelitian yang dilakukan oleh Etnic Comitte of Hospital Clinicals, Faculty of Medicine in Brazill tercatat 40 pasien yang terdiagnosis dengna epistaksis dimana 27 pasien (67,5\%) adalah perempuan dan 13 pasien (32,5\%) laki-laki. Usia berkisar antara 4 sampai 78 tahun, tetapi rata-rata terjadi pada usia 20-40 tahun, dan usia anak SD. Faktor predisposisi dimana 15 pasien (37,5\%) epistaksis muncul sebagai komplikasi paska operasi dalam prosedur bedah THT (septoplasty dikombinasikan atau tidak dengan turbinectomy, adenotonsilectomy, rhinoplasty, atau bedah sinus paranasal endoskopi), 24 pasien (53\%) mengalami perdarahan paska operasi segera $(<48$ jam $)$ dan semua yang lain telah perdarahan episode setelah 48 jam pertama. Hanya satu pasien memiliki riwayat trauma hidung.

\section{METODE PENELITIAN}

Penelitian ini bersifat deskriptif retrospektif. Semua penderita yang terdiagnosa epistaksis di poliklinik THT-KL BLU RSUP Prof. DR. R.D Kandou Manado sejak Januari 2010 - Desember 2012.

\section{HASIL DAN PEMBAHASAN}

Berdasarkan data yang diperoleh dari penelitian retrosepktif yang telah dilakukan terhadap penderita epistaksis periode Januari 2010 - Desember 2012 di poliklinik THTKL BLU RSUP Prof. DR. R.D. Kandou Manado, ditemukan 1048 penderita epistaksis dari 12.981 pasien. Berdasarkan hasil yang diperoleh pada tahun 2010 menunjukkan distibusi frekuensi penderita terbanyak pada bulan Juli 36 kasus (8,16\%) sedangkan pada bulan Desember 10 kasus (5,15\%). Pada tahun 2011, bulan Oktober terjadi 50 kasus $(13,74 \%)$ sedangkan bulan Februari 20 kasus (5,49\%). Tahun 2012 hasil yang didapat terbanyak pada bulan Oktober 37 kasus (9,87\%) sedangkan pada bulan Desember 11 kasus (2,98\%). Berdasarkan data yang ada terlihat adanya perbedaan pada beberapa bulan, ada yang tinggi dan ada pula yang rendah.

Pada Tabel 1 jumlah total penderita epistaksis periode tahun 2010 adalah sebanyak 293 orang (7,07\%) dari 4227 pasien yang datang berobat di poliklinik THT-KL BLU RSUP Prof. DR. R.D. Kandou Manado. Angka kejadian tertinggi pada tahun 2010 adalah bulan Juli 36 kasus $(8,16 \%)$ dan yang terendah pada bulan Desember 10 kasus (5,15\%).

Tabel 1. Distribusi jumlah penderita epistaksis

\begin{tabular}{cccccccccc}
\hline \multirow{2}{*}{ Bulan } & \multicolumn{3}{c}{ Jumlah Pengunjung } & \multicolumn{3}{c}{ Jumlah penderita } & \multicolumn{3}{c}{ Persentase (\%) } \\
\cline { 2 - 10 } & 2010 & 2011 & 2012 & 2010 & 2011 & 2012 & 2010 & 2011 & 2012 \\
\hline Januari & 387 & 448 & 304 & 28 & 29 & 28 & 7.24 & 6.47 & 9.21 \\
Februari & 329 & 364 & 404 & 25 & 20 & 25 & 7.60 & 5.49 & 6.19 \\
Maret & 347 & 719 & 380 & 27 & 46 & 31 & 7.78 & 6.40 & 8.16 \\
April & 358 & 424 & 373 & 25 & 36 & 32 & 6.98 & 8.49 & 8.58 \\
Mei & 386 & 285 & 321 & 29 & 34 & 28 & 7.51 & 11.93 & 8.72 \\
Juni & 393 & 388 & 403 & 29 & 45 & 26 & 7.38 & 11.60 & 6,45 \\
Juli & 441 & 502 & 381 & 36 & 45 & 31 & 8.16 & 8.96 & 8.14 \\
Agustus & 372 & 407 & 302 & 23 & 34 & 20 & 6.18 & 8.35 & 6.62 \\
September & 377 & 332 & 423 & 27 & 39 & 28 & 7.16 & 11.75 & 6.62 \\
Oktober & 346 & 364 & 375 & 21 & 50 & 37 & 6.07 & 13.74 & 9.87 \\
November & 297 & 378 & 424 & 19 & 34 & 14 & 6.40 & 8.99 & 3.30 \\
Desember & 194 & 314 & 369 & 10 & 26 & 11 & 5.15 & 8.28 & 2,98 \\
\hline Total & 4227 & 4295 & 4459 & 293 & 438 & 311 & 7.07 & 10.2 & 7.66 \\
\hline
\end{tabular}




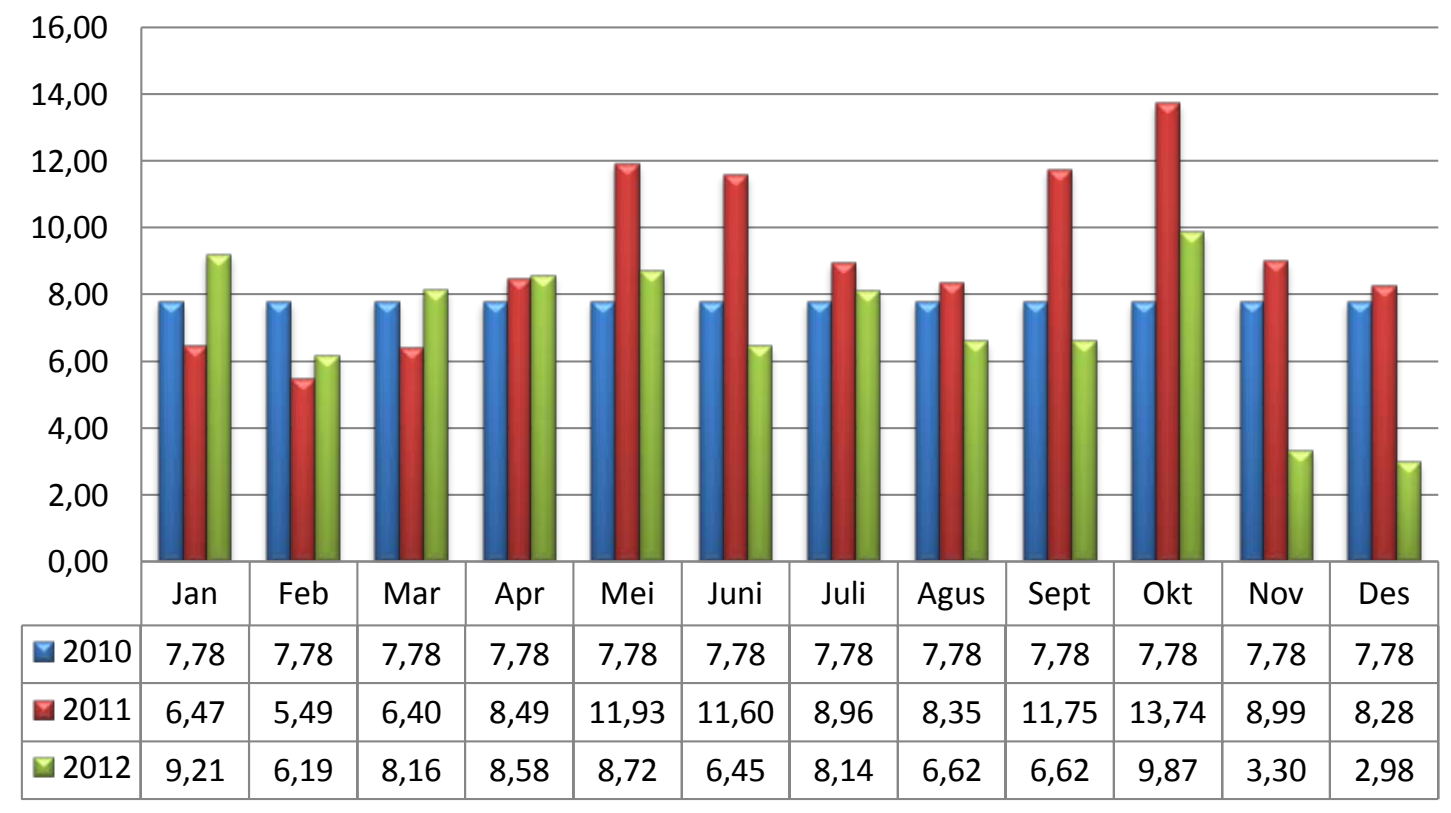

Gambar 1. Distribusi frekuensi berdasarkan jumlah penderita

Tabel 2. Distribusi frekuensi berdasarkan jenis kelamin

\begin{tabular}{ccccccccc}
\hline Jenis & \multicolumn{2}{c}{$\mathbf{2 0 1 0}$} & \multicolumn{2}{c}{$\mathbf{2 0 1 1}$} & \multicolumn{2}{c}{$\mathbf{2 0 1 2}$} & \multicolumn{2}{c}{ Total } \\
kelamin & $\mathrm{n}$ & $\%$ & $\mathrm{n}$ & $\%$ & $\mathrm{n}$ & $\%$ & $\mathrm{n}$ & $\%$ \\
\hline Laki-laki & 150 & 50,17 & 222 & 50,68 & 161 & 51,77 & 533 & 50,86 \\
Perempuan & 149 & 49,83 & 216 & 49,32 & 150 & 48,23 & 515 & 49,14 \\
Total & 299 & 100 & 438 & 100 & 311 & 100 & 1048 & 100 \\
\hline
\end{tabular}

Pada tahun 2011, angka kejadian tertinggi pada bulan Oktober 50 kasus $(13,74 \%)$ dan yang terendah pada bulan Februari 20 kasus (5,49\%).

Pada tahun 2012, angka kejadian tertinggi untuk jumlah penderita epistaksis terjadi pada bulan Oktober 37 kasus (9,87\%) dan terendah pada bulan Desember 11 kasus (2,98\%).

Distribusi berdasarkan jenis kelamin yang didapatkan pada penelitian ini adalah penderita laki-laki lebih banyak dibandingkan penderita perempuan, walaupun tidak ada perbedaan yang terlalu jauh antara jumlah penderita laki-laki dan perempuan. 533 pasien laki-laki dengan persentasi 50,86\% dan perempuan 515 pasien dengan persentasi 49,14\% dari total 1048 penderita selama periode Januari 2010-Desember 2012.

Hasil diatas menunjukkan bahwa jumlah penderita epistaksis lebih banyak ditemukan pada laki-laki bisa dihubungkan dengan penyebab hipertensi, dimana suatu referensi menyebutkan tekanan darah pria lebih tinggi dibandingkan wanita, dan hipertensi merupakan suatu penyebab epistaksis yang paling sering yakni epistaksis dengan penyebab sistemik. Selain itu juga epistaksis lebih banyak ditemukan pada pria bisa dihubungkan dengan pola hidup.

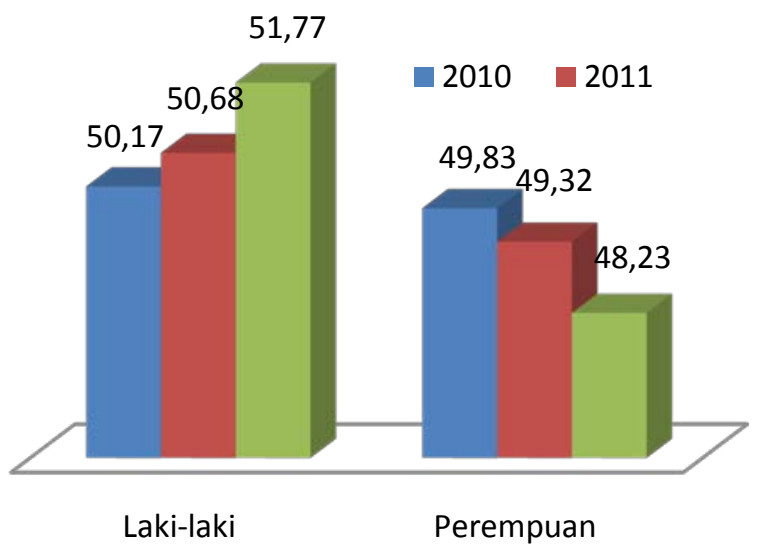

Gambar 2. Distribusi frekuensi berdasarakan jenis kelamin. 
Tabel 3. Distribusi frekuensi berdasarkan umur

\begin{tabular}{ccccccccc}
\hline \multirow{2}{*}{ Umur } & \multicolumn{2}{c}{$\mathbf{2 0 1 0}$} & \multicolumn{2}{c}{$\mathbf{2 0 1 1}$} & \multicolumn{2}{c}{$\mathbf{2 0 1 2}$} & \multicolumn{2}{c}{ Total } \\
& $\mathrm{n}$ & $\%$ & $\mathrm{n}$ & $\%$ & $\mathrm{n}$ & $\%$ & $\mathrm{n}$ & $\%$ \\
\hline$<1$ & 2 & 0.67 & 1 & 0.23 & 0 & 0 & 3 & 0,29 \\
$1-4$ & 9 & 3.01 & 7 & 1.60 & 4 & 1.29 & 20 & 1,91 \\
$5-14$ & 17 & 5.69 & 41 & 9.36 & 27 & 8.68 & 85 & 8,11 \\
$15-24$ & 38 & 12.71 & 40 & 9.13 & 42 & 13.50 & 120 & 11,45 \\
$25-44$ & 99 & 33.11 & 161 & 36.76 & 121 & 38.91 & 381 & 36,35 \\
$45-64$ & 110 & 36.79 & 149 & 34.02 & 98 & 31.51 & 357 & 34,06 \\
$>65$ & 24 & 8.03 & 39 & 8.90 & 19 & 6.11 & 82 & 7,82 \\
total & 299 & 100 & 438 & 100 & 311 & 100 & 1048 & 100 \\
\hline
\end{tabular}

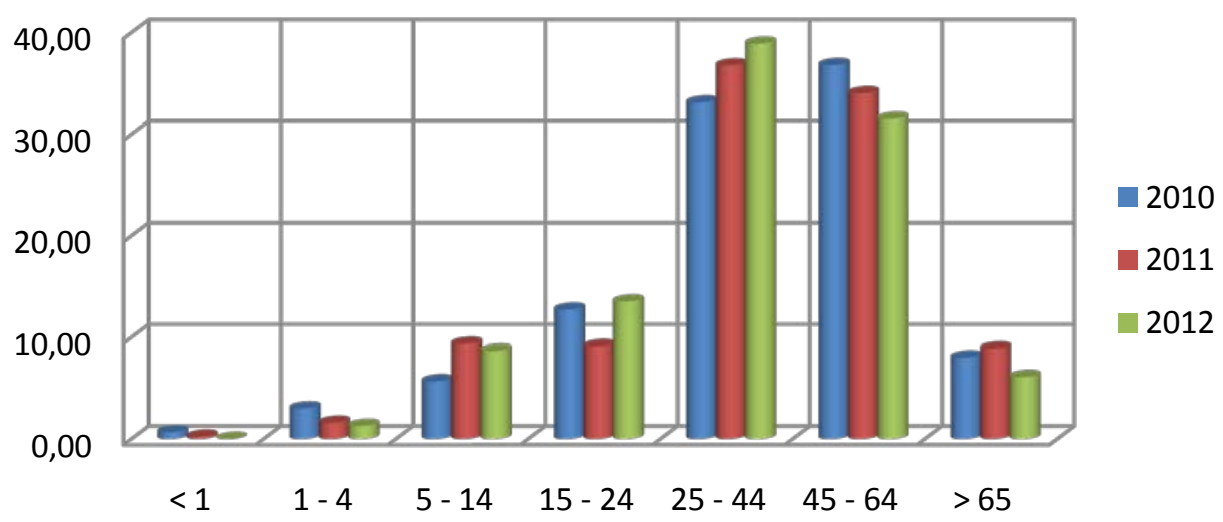

Grafik 3. Distribusi frekuensi berdasarkan umur.

Tabel 4. Distribusi frekuensi berdasarkan penyebab

\begin{tabular}{ccccccccc}
\hline \multirow{2}{*}{ Penyebab } & \multicolumn{2}{c}{$\mathbf{2 0 1 0}$} & \multicolumn{2}{c}{$\mathbf{2 0 1 1}$} & \multicolumn{2}{c}{$\mathbf{2 0 1 2}$} & \multicolumn{2}{c}{ Total } \\
\cline { 2 - 9 } & $\mathbf{n}$ & $\mathbf{\%}$ & $\mathbf{n}$ & $\mathbf{\%}$ & $\mathbf{n}$ & $\mathbf{\%}$ & $\mathbf{n}$ & $\mathbf{\%}$ \\
\hline Lokal & 119 & 39,80 & 170 & 38,81 & 98 & 31,51 & 387 & 36,93 \\
Sistemik & 172 & 57.53 & 241 & 55.02 & 200 & 64.31 & 613 & 58,49 \\
Dll & 8 & 2.68 & 27 & 6.16 & 13 & 4.18 & 48 & 4,58 \\
Total & 299 & 100 & 438 & 100 & 311 & 100 & 1048 & 100 \\
\hline
\end{tabular}

Suatu literatur mengemukakan bahwa pasien yang mengkonsumsi alkohol tinggi secara teratur meningkatkan resiko terjadinya epistaksis, dan kebanyakan kebiasaan mengkonsumsi alkohol lebih banyak pada pria dibanding-kan wanita.

Epistaksis dapat mengenai semua golongan umur. Berdasarkan tabel distribusi penderita epistaksis menurut umur dengan jumlah 1048 penderita, kelompok umur yang paling banyak persentasinya yaitu kelompok umur 25-44 tahun dengan jumlah
381 penderita (36,35\%). Hal ini dikarenakan pada penderita epistaksis pada kelompok umur $<20$ tahun, umumnya spontan dan dapat berhenti sendiri, sehingga pasien dengan kelompok umur tersebut jarang dibawa ke rumah sakit, sedangkan pada penderita episksis dengan kelompok umur dewasa tua, umumnya lebih berat dan jarang berhenti sendiri, sehingga penderita akan mencari bantuan medis.

Pada penelitian ini distribusi berdasarkan penyebab epistaksis yang 
terbanyak adalah penyebab sistemik yaitu 613 penderita (58,49\%). Epistaksis dengan penyebab sistemik ini sering ditemukan pada pasien dengan hipertensi, perdarahan biasanya lebih hebat dan jarang berhenti sendiri. Kemudian disusul dengan penyebab lokal dengan jumlah penderita sebanyak 387 orang (36,93\%).

Pada hasil penelitian dimana penyebab sistemik lebih banyak ditemukan dibandingkan dengan penyebab lokal bisa dihubungkann dengan golongan umur terbanyak yang didapat, dimana kelompok umur $>25$ tahun lebih banyak ditemukan dibandingkan kelompok umur $<25$ tahun. Hubungannya adalah penyebab sistemik yang sering ditemukan pada pasien dengan hipertensi lebih banyak ditemukan pada pasien dengan kelompok umur $>25$ tahun atau dewasa tua, sedangkan untuk penyebab lokal sendiri terdiri dari beberapa yaitu trauma, seperti mengeluarkan sekret dengan kuat, bersin, trauma seperti terpukul, jatuh dan sebagainya.

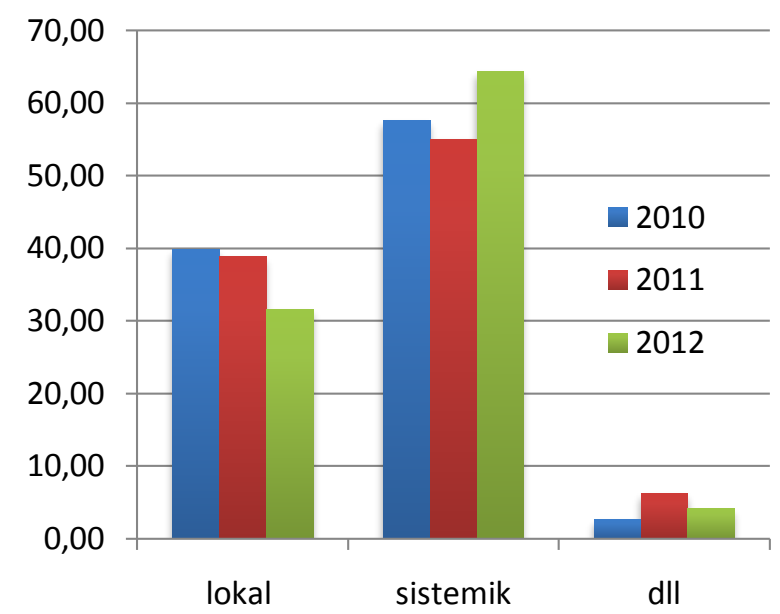

Grafik 4. Distribusi frekuensi berdasarkan penyebab

\section{SIMPULAN DAN SARAN}

Berdasarkan hasil penelitian tentang epistaksis yang dilakukan di Poliklinik THT-KL BLU RSUP Prof. DR. R.D. Kandou Manado periode Januari 2010 Desember 2012, dapat disimpulkan bahwa jumlah penderita epistaksis adalah 8,07\%, ditemukan penderita laki-laki dengan angka kejadian lebih tinggi dibandingkan perempuan, penderita epistaksis lebih banyak ditemukan pada umur 25-44 tahun, penyebab terbanyak penderita epistaksis adalah penyebab sistemik yaitu sebanyak 613 penderita $(58,49 \%)$.

Setelah melakukan penelitian ini, penulis mengharapkan adanya penelitian lebih lanjut tentang epistaksis agar kita dapat menilai peningkatan ataupun penurunan insiden epistaksis, dan upaya penanggulangan epistaksis sebaiknya dilakukan sedini mungkin dan dilakukan secara tepat sebab epistaksis jika tidak ditangani perdarahannya dapat menyebabkan komplikasi yang berbahaya.

\section{DAFTAR PUSTAKA}

1. Mangunkusumo, E and Wardani, Retno. Perdarahan Hidung dan Gangguan Penghidu. [ed.] E A Soepardi, N Iskandar and R D Restuti. Jakarta: Fakultas Kedokteran Universitas Indonesia, 2007. pp. 155-159.

2. Epistaxis. Eziyi JAE, Akinpelu OV, Amusa YB, Eziyi, E K;. 2009, East and Central American Journal, pp. 93-94.

3. Epidemiology of Epistaxis in a Canadian Emergency Department. Nash, $\mathbf{C} \mathbf{M}$; Simon, F;. 2008, Israeli Jurnal of Emergency Medicine, Vol. 8, pp. 23-24.

4. Endovascular Treatment of Epistaxis. Willms, P W A; Farb, R I; Agid, R;. 2009, American Journal of Neuroradiology, Vol. 30, p. 1637.

5. Surgical Treatment of Nasal Packing Refractory Epistaxis. Rabelo, F A W; Prado, V B; Valera, F C; Damrco, R C; Tamashiro, E; Lima, W T A;. 2009, Brazilian Journal of Otohirolaryngology, Vol. 75 (3).

6. Munir, D Y; Haryono, A Y M; Rambe;. Epistaxis. 2006. Vol. 39 (3), pp. 274-277.

7. Mansjoer, A K; Triyanti, R; Savitri, W I; Wardhani, W; Setiowulan;. Kapita Selekta Kedokteran. Jakarta : Fakultas Kedokteran UI, 2001.

8. Health, Medical Center. http:??medicalcenter-

health.blogspot.com/2010/12/anatomihidung-nasofaring-sistem.html?m=1. [Online] 2010. [Cited: oktober 23, 2012.]

9. Iskandar, $\mathbf{H} \mathbf{N}$;. Ilmu Penyakit Telinga Hidung Tenggorok. Jakarta : FKUI, 2006. 
10. Lucente, F E; Har-El, G; Goldsmith, A J; Sperling, N M; Turk, J B;. Ilmu THT Esensial. Jakarta: Buku Kedokteran EGC, 2011.

11. Soperadi, E A; Iskandar, N; Bashiruddin, J; Restuti, R D;. Buku Ajar Ilmu Kesehatan Telinga Hidung Tengorok Kepala \& Leher. Jakarta: FKUI, 2007.

12. Van Den Broek, P, Feenstra L. Hidung dan Sinus Paranasal. Jakarta : EGC, 2009. p. $124 \& 178$.

13. Widodo http://koranindonesiasehatworpress.com. [Online] [Cited: Oktober 24, 2012.]

14. Kuak, $\mathbf{C} \mathbf{J}$ and Clenney, T. Manajemen of Epistaxis. s.l. : American Family Physician, 2005. pp. 305-311. Vol. 72 .
15. Suryowati, E. http://FKUI.org.tikidownload_wiki_attachment. [Online] Medical Study Club FKUI. [Cited: Oktober 24, 2012.]

16. Reichmen, $E$ F and Simon, $R \quad R$. http://www.Jevuska.com/2010/07/08/epistak sis-perdarahan-hidung. [Online] [Cited: Oktober 25, 2010.]

17. Ichsan, M. Penatalaksanaan Epistaksis. s.l. : Cermin Dunia Kesehatan, 2001.

18. Arfianti, E. http://www.emedicine.com. [Online] 2005. [Cited: Oktober 25, 2012.]

19. Ballenger, J J. Penyakit Telinga Hidung Tenggorok Kepala dan Leher. Jakarta : EGC, 1994. Vol. 13. 